\title{
¿POR QUÉ TENGO QUE PAGAR YO LAS DEUDAS DE SUMINISTROS DE AGUA Y LUZ QUE EL ANTERIOR OCUPANTE DEJÓ SIN PAGAR?*
}

\author{
Elena Trujillo Villamor \\ Centro de Estudios de Consumo \\ Universidad de Castilla-La Mancha
}

Resumen: Análisis a la problemática presentada por consumidores cuando adquieren una nueva propiedad y existen deudas anteriores de suministros energéticos. En este documento se plantean las opciones que tienen estos consumidores para regularizar su situación y las posibles actuaciones de las empresas suministradoras.

Palabras clave: Cargas, propter rem, obligaciones personales, suministro, nuevo alta, titularidad.

Title: Why do I have to pay for the water and power debts incurred by the previous owner?

\footnotetext{
* Trabajo realizado en el marco del Contrato con referencia 2020-COB-9847 financiado con cargo al Proyecto Convenio de colaboración entre la UCLM y el Ilustre Colegio Notarial De Castilla-La Mancha (17 enero 2014) (OBSV) con referencia CONV140025, que dirige el Prof. Ángel Carrasco Perera; en el marco del Proyecto de Investigación PGC2018-098683-B-I00, del Ministerio de Ciencia, Innovación y Universidades (MCIU) y la Agencia Estatal de Investigación (AEI) cofinanciado por el Fondo Europeo de Desarrollo Regional (FEDER) titulado "Protección de consumidores y riesgo de exclusión social", dirigido por Ángel Carrasco Perera y Encarna Cordero Lobato; a la Ayuda para la financiación de actividades de investigación dirigidas a grupos de la UCLM Ref.: 2020-GRIN-29156, denominado "Grupo de Investigación del Profesor Ángel Carrasco" (GIPAC) y a la ayuda para la realización de proyectos de investigación científica y transferencia de tecnología, de la Junta de Comunidades de Castilla-La Mancha cofinanciadas por el Fondo Europeo de Desarrollo Regional (FEDER) para el Proyecto titulado "Protección de consumidores y riesgo de exclusión social en Castilla-La Mancha" (PCRECLM) con Ref.: SBPLY/19/180501/000333 dirigido por Ángel Carrasco Perera y Ana Isabel Mendoza Losana.
} 


\begin{abstract}
Analysis of new property owners facing previous owners' energetic supplies debts. This report sets out the different consumers options in order to regularize this situation as the supplyng companies possibilities.
\end{abstract}

Keywords: Charges, propter rem, personal duties, supplies, new contract, ownership.

SUMARIO: 1. Planteamiento. 2. ¿Qué resuelve la normativa sectorial de los contratos de suministro? 3. ¿Qué establece la jurisprudencia? 4. ¿Cómo se pronuncia la CNMC? 5. ¿Obligación real o personal? 6. Problemática: prácticas de las empresas suministradoras. 6.1. Primer supuesto: El nuevo propietario satisface la deuda anterior a ser usuario efectivo de la energía. 6.2. Segundo supuesto: El nuevo propietario no satisface la deuda anterior a ser usuario efectivo de la energía. 6.3. Tercer supuesto: El nuevo propietario disfruta de los suministros sin subrogarse, cambiar la titularidad o dar un nuevo alta y no paga las facturas relativas a su consumo. 7. Conclusiones. 8. ¿Qué ocurriría con la Tasa de Residuos Urbanos? 9. Bibliografía.

\title{
1. Planteamiento
}

En un supuesto de compraventa de un bien inmueble con suministros de energía contratados por el anterior propietario se plantean diversas preguntas que serán analizadas a continuación ¿quién debe hacer frente a deudas contraídas por el anterior propietario del inmueble? ¿Frente a quién puede reclamar la empresa suministradora? ¿Puede beneficiarse el nuevo propietario de los suministros al no ser parte contractual? ¿Qué opciones tiene la empresa suministradora para satisfacer las deudas? ¿Cuál es la naturaleza de las cargas relativas a esos servicios asociados a un bien inmueble?

\section{2. ¿Qué resuelve la normativa sectorial de los contratos de suministro?}

En cuanto al suministro de gas, este se encuentra regulado en la Ley $34 / 1998$, de 7 de octubre, del sector de hidrocarburos ${ }^{1}$ modificada para adaptarla a las directivas europeas ${ }^{2}$. Este sector también ha sido regulado por el Real Decreto 1434/2002, de 27 de diciembre, por el que se regulan las actividades de transporte, distribución, comercialización, suministro y procedimientos de autorización de instalaciones de gas natural $^{3}$ (en adelante, RD 1434/2002) y en el Real Decreto 1085/1992, de 11 de septiembre, por el que se aprueba el Reglamento de la actividad de distribución de gases licuados del petróleo ${ }^{4}$ (en adelante, RD 1085/1992) ${ }^{5}$.

\footnotetext{
${ }^{1}$ BOE núm. 241, 8 de octubre de 1998.

2 Ley 12/2007, de 2 de julio, por la que se modifica la Ley 34/1998, de 7 de octubre, del Sector de Hidrocarburos, con el fin de adaptarla a lo dispuesto en la Directiva 2003/55/CE del Parlamento Europeo y del Consejo, de 26 de junio de 2003, sobre normas comunes para el mercado interior del gas natural.

${ }^{3}$ BOE núm. 313, 31 de diciembre de 2002

${ }^{4}$ BOE núm. 243, 9 de octubre de 1992

${ }^{5}$ El RD 1085/1992 se entenderá derogado cuando se oponga al RD 919/2006
} 
En el artículo 36.2 del RD 1434/2002 se establece que «El contrato de suministro es personal, y su titular deberá ser el efectivo usuario del combustible, que no podrá utilizarlo en lugar distinto para el que fue contratado, ni cederlo, ni venderlo a terceros». Esta disposición no significa que el contrato no goce de naturaleza real sino simplemente que no se trata de una obligación de propter rem, es decir, que el nuevo propietario del bien inmueble no se convertirá en sujeto pasivo de la relación jurídica obligatoria nacida en virtud de un contrato anterior a la adquisición de la vivienda.

Otra disposición que ahonda sobre la no caracterización de estos contratos como cargas proter rem es el artículo 27 del RD 1085/1992 ${ }^{6}$. Esta obligación de formalizar un contrato nuevo de suministro por otra persona permite apreciar la característica personal que califica al contrato de suministro de gas y su imposibilidad de transmitirse con el derecho real de propiedad.

Al efecto, cabe destacar el artículo 26.b) de la misma normativa, que determina las causas de denegación del suministro de gas y entre ellas se encuentra el impago del suministro por el peticionario en cualesquiera domicilios en los que se hubiese producido el impago del suministro relativo a ese bien inmueble. Lo que vuelve a poner de manifiesto que el contrato de suministro «persigue» al contratante del suministro y no permanece con el bien inmueble para el cual fue suscrito, lo que deriva en la no afección del contrato de suministro al bien inmueble y su definición como carga personal.

El sector de energía eléctrica se encuentra regulado en la Ley 24/2013, de 26 de diciembre, del Sector Eléctrico ${ }^{7}$. Al igual que con el sector gasista, los suministros de luz también han sido regulados y desarrollados por Reales Decretos, así se pueden poner de relieve el Real Decreto 1955/2000, de 1 de diciembre, por el que se regulan las actividades de transporte, distribución, comercialización, suministro y procedimientos de autorización de instalaciones de energía eléctrica ${ }^{8}$ (en adelante, RD 1955/2000).

El artículo 79.3 del RD 1955/2000 establece «El contrato de suministro es personal, y su titular deberá ser el efectivo usuario de la energía, que no podrá utilizarla en lugar distinto para el que fue contratada, ni cederla, ni venderla a terceros». Esta disposición al igual que ocurre con la relativa al contrato de gas no establece que no sea una obligación real, simplemente viene a poner de manifiesto que las obligaciones derivadas de esta relación contractual no tienen naturaleza propter rem.

En efecto, de la legislación analizada cabe concluir que los contratos de suministros no pueden calificarse como una obligación propter rem, esto significa que las

\footnotetext{
6 «Al cesar el titular del contrato por cualquier causa en la utilización y consumo de gas, se obliga a comunicarlo a la empresa suministradora, cursando su baja y procediéndose a la resolución del contrato. El traslado de domicilio de la persona que suscribió el contrato de suministro y la ocupación del mismo por persona diferente exigirá la formalización de un nuevo contrato de suministro».

7 BOE núm. 310, 27 de diciembre de 2013.

${ }^{8}$ BOE núm. 310, 27 de diciembre de 2000.
} 
obligaciones derivadas de esta relación contractual no se transmiten con el cambio en la titularidad del derecho real. Pero el hecho de que no se consideren una obligación propter rem no implica necesariamente que no se consideren una carga real, es decir, que las obligaciones del contrato de suministro se encuentren afectas al bien raíz. Esto produciría una acción real sobre la cosa para el supuesto de incumplimiento de las obligaciones relativas a la relación contractual de los suministros.

\section{3. ¿Qué establece la jurisprudencia?}

Relativo a los impagos del suministro de gas se pone de manifiesto la Sentencia de la Audiencia Provincial de Madrid (Sección 12a) núm. 599/2006 de 26 septiembre (JUR\2006\268778) donde la parte actora (compañía suministradora de gas) presentó demanda en reclamación de cantidad por consumo de gas impagado durante dos años. El titular del contrato de gas, antiguo propietario de la vivienda alega que no tiene que hacer frente a las deudas debido a la venta del piso al que hace referencia ese suministro. La AP entiende que aunque el propietario vendió el inmueble al que hace referencia la póliza contratada con la empresa suministradora de gas, no ha comunicado su decisión de dar por extinguido el contrato, ni su voluntad de darlo por resuelto, ni de cederlo a un tercero, por tanto, es de aplicación el principio de relatividad de los contratos, éstos sólo producen efecto entre las partes que los otorgan y sus herederos, todo ello conforme a los principios generales de las obligaciones y contratos, plasmados en los artículos $1.254,1.256$ del CC.

De igual forma se pronuncia la AP de Barcelona (Sección 13a) en su sentencia núm. $65 / 2010$ de 4 febrero (JUR\2010\147973). En este caso, la compañía suministradora de gas presentó demanda en reclamación de las facturas por consumo de gas impagadas al antiguo propietario del bien inmueble y titular del contrato. El demandado se opuso e invocó la excepción de falta de legitimación pasiva. Sostuvo que había vendido la vivienda a terceros en fecha muy anterior a los períodos por que se reclaman los suministros y que la deuda debía exigirse a sus actuales propietarios. El Tribunal reconoce que efectivamente la demandada no pudo realizar los consumos cuyo precio se reclama, desde la fecha de la venta del inmueble, pero no es óbice para seguir siendo considerado parte contratante, ya que, no actuó de forma coherente y diligente y nunca resolvió el contrato de suministro con la compañía de gas. Por ello, a pesar de que es cierto que no ha disfrutado de los suministros que se le reclaman, el Tribunal conforme al artículo 1257 del CC interpreta que quién debe cargar con las deudas no satisfechas es el titular del contrato de suministro, sin olvidar la posibilidad de una vez abonada la suma total reclamada, poder dirigirse contra los propietarios actuales y aquellos que han disfrutado de forma efectiva los suministros ${ }^{9}$.

Así, la AP de Barcelona (Sección 1a) en su Sentencia núm. 395/2010 de 28 septiembre (JUR\2010\374542) insiste en el carácter personal de la deuda generada

\footnotetext{
${ }^{9}$ En la misma línea se pronuncia la AP de Barcelona (Sección 14a) Sentencia núm. 710/2009 de 29 octubre (JUR\2009\488334).
} 
por suministros impagados de gas, cuando la empresa distribuidora de gas interpone demanda contra los propietarios actuales del bien inmueble por impago del suministro y ve desestimada su pretensión, porque aunque sean los usuarios reales del consumo, no cabe estimar la reclamación de la deuda frente a quiénes no son parte contratante o titulares de la póliza de suministro, ni consta su subrogación ${ }^{10}$.

Relativo a los impagos del suministro de energía eléctrica se pone de manifiesto la Sentencia de la Audiencia Provincial de Valencia (Sección 8a) núm. 209/2013 de 8 mayo (JUR\2013\286438) donde la compañía suministradora de energía eléctrica demandó al antiguo propietario por impagos del servicio y éste se opuso alegando que no era el verdadero consumidor del suministro. Interpreta la AP que aunque el demandado no es el propietario actual de la vivienda, al no haber comunicado a la actora tal eventualidad, con el fin de extinguir la obligación contraída, cabe entender que seguía vigente el vínculo contractual y por tanto era el responsable del pago de la energía eléctrica consumida en el período reclamado y hasta la comunicación de la baja, sin perjuicio de su acción de repetición contra el efectivo usuario del suministro aplicando así la teoría general de los contratos (art.1257 CC). El hecho de que el demandado haya cesado en el disfrute del servicio no le exime, sin más, de su pago, pero sin perjuicio de las acciones de repetición a que hubiere lugar, en el plano jurídico, los obligados frente a la empresa distribuidora de energía eléctrica son los titulares del contrato de suministro ${ }^{11}$.

\section{4. ¿Cómo se pronuncia la CNMC?}

La Comisión Nacional de Mercados y de la Competencia (en adelante, CNMC) realizó un informe sobre una consulta remitida por una empresa sobre a quien corresponde sufragar las facturas impagadas de suministros de gas pendientes tras la venta de una vivienda particular ${ }^{12}$.

La controversia esbozada ante la CNMC se trata del supuesto de un nuevo propietario que ha adquirido un bien inmueble con una deuda anterior de suministro de gas y la CNMC debe interpretar si de acuerdo con la normativa aplicable a la naturaleza de

\footnotetext{
${ }^{10}$ En la misma línea se pronuncia la AP de Madrid (Sección 25a) Sentencia núm. 85/2012 de 13 febrero (JUR\2012\112172), que, frente a un caso de demanda contra el anterior propietario y la oposición de este por no ser el consumidor real del servicio, determina que se trata de un problema de partes del contrato y éstas son las que intervienen en el actual contrato litigioso, es decir, el demandado con independencia de quién ocupe el local o vivienda. de conformidad con lo establecido por el artículo 1257 del CC, los contratos sólo producen efecto entre las partes que los otorgan y sus herederos. De este modo, vigente la relación contractual establecida entre las partes es indudable que el responsable, frente al suministrador, de la obligación de pago de los suministros por éste efectuados lo será, siempre y en todo caso, el usuario conforme al contrato. "o El firmante de la póliza debe de responder de los consumos realizados, con independencia de que haya sido o no el usuario del gas, toda vez que no se ha dado de baja en el contrato".

11 Audiencia Provincial AP de Islas Baleares (Sección 3a) Sentencia núm. 181/2014 de 2 junio JUR\2014\180621

12 COMISIÓN NACIONAL DE ENERGÍA, "Informe sobre la consulta remitida por una empresa sobre a quien corresponde sufragar las facturas impagadas de suministros de gas pendientes tras la venta de una vivienda particular". Mayo 2012. (8 páginas). Disponible en https://www.cnmc.es/expedientes/cne1812
} 
los contratos de suministros, específicamente el contrato de suministro de gas, debe ser una obligación del nuevo propietario.

La empresa comercializadora de gas argumenta que, si en la escritura de compraventa no indica expresamente nada sobre las deudas de servicios esenciales, recaerá la obligación de pagar las deudas pendientes en el nuevo propietario. Si el nuevo propietario quiere que las deudas pendientes asociadas al inmueble sean satisfechas por el anterior propietario podrá acudir a dos fórmulas, la primera opción es hacer constar de manera fehaciente a través de la escritura de compraventa que esta obligación recaerá sobre el anterior propietario, la segunda opción es la mención de no haber podido conocer el estado de los gravámenes de los contratos de servicios esenciales que se encuentran asociados al bien inmueble.

La CNMC analiza este argumento, el cual atiende a que la naturaleza de los contratos de suministros esenciales asociados a un bien inmueble reviste carácter de garantía real, y termina por pronunciarse contra este argumento.

Así, la CNMC fija su criterio en la naturaleza personal de los contratos de suministros conforme al artículo 1257 del CC y conforme al artículo 36.2 del Real Decreto $1434 / 2002$, de 27 de diciembre que establecen que el contrato de suministro es de carácter personal e invierte así el argumento esgrimido por la empresa comercializadora de gas. Si el anterior propietario del bien inmueble quiere que el nuevo propietario quede vinculado por su contrato de suministro de gas y se haga cargo de las deudas pendientes debe recabar su consentimiento expreso ${ }^{13}$.

\section{5. ¿Obligación real o personal?}

Una vez analizado la normativa sectorial, la jurisprudencia y el pronunciamiento de la CNMC se ha determinado que los cargas relativas a los contratos de suministros energéticos no ostentan naturaleza propter rem. Sin embargo, no se ha definido aún si estas cargas gozan de naturaleza personal o real. En busca de determinar esta naturaleza hay dos argumentos que inducen a la solución a esta controversia.

El Registro de la Propiedad es uno de estos argumentos. Si el nuevo propietario acudiese al Registro de la Propiedad para que se expidiese un certificado de que el bien inmueble que va a adquirir se encuentra libre de cargas, no impedirá la emisión de tal certificado las deudas relativas a los suministros de energía impagados. Esto significa que las obligaciones relativas a estos contratos no gozan de naturaleza real.

En el Registro de la Propiedad la condición previa para poder proceder a su inscripción y gozar así de la publicidad registral es la naturaleza real del derecho (art. 2 de la Ley Hipotecaria $)^{14}$ lo que deja fuera de su ámbito de actuación a todos aquellos contratos

\footnotetext{
13 FERNÁNDEZ BENAVIDES, M., "¿Quién debe sufragar las facturas impagadas de suministros de gas pendientes tras la venta de la vivienda?" Web del Centro de Estudios de Consumo de la Universidad de Castilla-La Mancha (http://www.uclm/cesco.es/). Junio 2012 (6 páginas).

14 "En los Registros expresados en el artículo anterior se inscribirán: Primero. Los títulos traslativos o declarativos del dominio de los inmuebles o de los derechos reales impuestos sobre los mismos..."
} 
personales de los cuales se deriven deudas personales oponibles inter partes y sin efectos frente a terceros, cuestión acaecida en los suministros esenciales.

Los contratos entre los propietarios o inquilinos de una vivienda con las empresas suministradoras de energía carecen de naturaleza real y por tanto no puede inscribirse en el Registro de la Propiedad (art.9 del Reglamento Hipotecario) ${ }^{15}$ e igualmente no se encuentran bajo la obligación establecida por el Código Civil en su artículo 1280: "Deberán constar en documento público: $1 .{ }^{\circ}$ Los actos y contratos que tengan por objeto la creación, transmisión, modificación o extinción de derechos reales sobre bienes inmuebles".

El otro argumento que apuntala la naturaleza personal de las cargas relativas a los contratos de suministro, es inexistencia de legislación que determine la afección de estas cargas al bien inmueble.

Finalmente, estos dos argumentos responden a la cuestión planteada, estableciendo la naturaleza personal de las cargas derivadas de los contratos de suministro. Si hubiese deudas impagadas de un periodo anterior a la adquisición del bien inmueble por el nuevo propietario, la empresa suministradora deberá reclamar al titular del contrato del suministro sea o no el propietario del bien o usuario efectivo de la energía.

\section{Problemática: prácticas de las empresas suministradoras}

A pesar de que las cargas de los suministros asociados a un bien inmueble ostentan una naturaleza personal, las empresas suministradoras intentan satisfacer esta deuda como si de una carga real se tratase, a través de prácticas tales como condicionar un nuevo alta para el nuevo propietario del bien inmueble al pago de las deudas anteriores.

Las compañías de electricidad y gas que reclaman al nuevo propietario las facturas impagadas por el anterior propietario incumplen con la normativa sectorial que se les aplica ${ }^{16}$, de igual forma ocurre con las altas para un nuevo contrato de suministro sujetos a condición.

Cuando una empresa suministradora de gas o electricidad deniegue el acceso al servicio a través de un nuevo contrato alegando motivos de impago de facturas por el dueño anterior, es una práctica que contraviene por completo la normativa y así se establece en el Real Decreto 1725/1984, de 18 de julio, por el que se modifican el Reglamento de Verificaciones Eléctricas y Regularidad en el Suministro de Energía y el modelo de póliza de abono para el suministro de energía eléctrica y las

\footnotetext{
15 "No son inscribibles la obligación de constituir, transmitir, modificar o extinguir el dominio o un derecho real sobre cualquier inmueble, o la de celebrar en lo futuro cualquiera de los contratos comprendidos en los artículos anteriores, ni en general cualesquiera otras obligaciones o derechos personales, sin perjuicio de que en cada uno de estos casos se inscriba la garantía real constituida para asegurar su cumplimiento o se tome anotación cuando proceda, de conformidad con el artículo cuarenta y dos de la Ley".

${ }^{16}$ Artículo 36.2 del RD 1434/2002, de 27 de diciembre. "el contrato de suministro es personal...".
} 
condiciones de carácter general de la misma ${ }^{17}$ en sus condiciones generales número $1^{18}$.

En el RD 1725/1984 se especifica una excepción a la obligatoriedad de dar suministro e igualmente pone de manifiesto la característica de la relación personal del contrato: "cuando se compruebe que el peticionario del suministro ha dejado de satisfacer el importe de la energía que haya consumido anteriormente de cualquier empresa suministradora de energía eléctrica". Impedir la obtención de un nuevo suministro a un peticionario que dejó impagados suministros anteriores recalca la aplicación del artículo 1257 del CC para este tipo de relación contractual, ya que la deuda del suministro no "se integra" con el inmueble, sino que seguirá al titular del contrato del suministro incluso impidiéndole dar de alta un nuevo suministro en otro bien inmueble. A su vez la condición general número 3 apdo.2 del RD 1725/1984 otorga la posibilidad de dar de alta un nuevo contrato de suministro para un bien inmueble, aunque éste sea objeto de otro contrato de suministro impagado.

Es indiferente el inmueble al cual vaya destinado el suministro contratado, siendo lo único relevante a la hora de hacer cumplir con las obligaciones del contrato las propias partes contratantes. El principio de relatividad de los contratos impide que se le reclame a un tercero (ajeno a la contratación) que cumpla con las obligaciones que solo atañen a las dos partes del contrato, aunque haya disfrutado de un servicio contratado por otro ${ }^{19}$.

Mucho más explícito es el RD 1434/2002 en la condición general número 3 apdo.2: «[...] no podrán negarse a suscribir la póliza de abono a un abonado que sea nuevo propietario o arrendatario del local, aunque el anterior sea deudor a la Empresa con facturaciones o recibos correspondiente al anterior, sin involucrar para nada al nuevo, al cual no se le podrá exigir la subrogación». Y así se ha recogido en páginas oficiales de suministradoras de energía ${ }^{20}$ y en la jurisprudencia ${ }^{21}$.

Esta afirmación pone de manifiesto las malas prácticas llevadas a cabo por las empresas suministradoras de servicio con las altas sujetas a condición de saldar deudas de un contrato de un titular anterior.

\footnotetext{
17 BOE núm. 230, 25 de septiembre de 1984.

18 "Las Empresas distribuidoras de energía eléctrica están obligadas a efectuar el suministro a todo peticionario del mismo, y a la ampliación del correspondiente a todo abonado final que lo solicite, en los términos establecidos por el vigente Reglamento de Acometidas, y a las tarifas eléctricas aprobadas oficialmente, debiendo prestar dicho suministro en las condiciones técnicas establecidas en el vigente Reglamento de Verificaciones Eléctricas y Regularidad en el Suministro de Energía".

19 PARRA LUCÁN, M.A., LALANA DEL CASTILLO, C., "La protección de los consumidores ante las empresas de telefonía, gas y electricidad. Estudio de cuestiones jurídicas". Oficina municipal de información al consumidor (OMIC). 2011.

https://www.solucionesintegralesendesa.com/media/wysiwyg/endesa/Condiciones/Condiciones pvp.pdf ${ }^{21}$ Tribunal Supremo (Sala de lo Contencioso-Administrativo, Sección3a) Sentencia de 24 febrero 2000. RJ $2000 \backslash 1333$
} 
Como conclusión, ninguna empresa suministradora de gas o electricidad puede imponer una cláusula o una condición general que sujete el alta de un servicio a saldar deudas de un titular anterior por ser abusiva ${ }^{22}$. Ello implicaría una renuncia de derechos del consumidor que sería nula, de acuerdo al artículo 83 del Real Decreto Legislativo 1/2007, de 16 de noviembre, por el que se aprueba el texto refundido de la Ley General para la Defensa de los Consumidores y Usuarios y otras leyes complementarias $^{23}$.

\section{a. Primer supuesto: El nuevo propietario satisface la deuda anterior a ser usuario efectivo de la energía}

Para el caso de que el nuevo propietario del bien inmueble satisfaga deudas anteriores ¿se consideraría que existe una subrogación tácita en el contrato?

Según la normativa sectorial del Real Decreto 1434/2002, en su artículo 39 y de acuerdo al RD 1955/2000 en su artículo 83, la subrogación en los contratos de suministro debe ser expresa no existiendo la posibilidad de aplicar el artículo 1205 del CC.

Más aclaratorio resulta el artículo 27 del Real Decreto $1085 / 1992^{24}$ que fija la obligación de formalizar un nuevo contrato cuando se produzca el traslado de domicilio de la persona que suscribió el contrato de suministro y la ocupación del mismo por persona diferente.

A mayor abundamiento, la operatividad del artículo 1205 se efectúa a través del consentimiento del acreedor y el hecho de que la empresa mercantil reclame al nuevo propietario del bien inmueble, es decir, el hecho de que la empresa distribuidora conozca el cambio del titular del inmueble no es requisito suficiente para que se acredite su consentimiento a la cesión del contrato de acuerdo al propio artículo 1205 del $\mathrm{CC}^{25}$.

No es menos cierto que la empresa suministradora aprobó un cambio en el número de cuenta para proceder a la domiciliación de los pagos de los suministros, por lo que no solo conocía la existencia de un nuevo titular en el bien inmueble, sino que había aceptado un cambio en el número de cuenta y de titular de la misma, lo que podría

\footnotetext{
${ }^{22}$ Artículo 82 TRLGDLCU: "Se considerarán cláusulas abusivas todas aquellas estipulaciones no negociadas individualmente y todas aquellas prácticas no consentidas expresamente que, en contra de las exigencias de la buena fe causen, en perjuicio del consumidor y usuario, un desequilibrio importante de los derechos y obligaciones de las partes que se deriven del contrato".

${ }^{23}$ BOE núm. 287, 30 de noviembre de 2007

24 «Al cesar el titular del contrato por cualquier causa en la utilización y consumo de gas, se obliga a comunicarlo a la empresa suministradora, cursando su baja y procediéndose a la resolución del contrato. El traslado de domicilio de la persona que suscribió el contrato de suministro y la ocupación del mismo por persona diferente exigirá la formalización de un nuevo contrato de suministro»

${ }^{25}$ De acuerdo a la Sentencia de la Audiencia Provincial de Madrid (Sección 25a) Sentencia núm. 85/2012 de 13 febrero (JUR\2012\112172) "no se justifica ni la cesión misma, ni, mucho menos, el consentimiento de la actora para tal transmisión, pues el hecho -por otra parte no cumplida y suficientemente justificadaque la actora tuviera conocimiento de que la vivienda ya no era ocupada por el aquí demandado, no es un hecho concluyente e inequívoco que permita por sí solo inferir la aquiescencia de la actora a la cesión del contrato".
} 
conllevar un indicio de consentimiento por parte del acreedor de subrogación. Sin embargo, parece que esta interpretación se aleja de la normativa propia del sector energético que se inclina por una subrogación expresa y numerosa jurisprudencia declara no identificar el conocimiento del cambio de titular mediante el cambio de una cuenta a domiciliar los pagos con el consentimiento expreso del acreedor ${ }^{26}$.

Sin discrepancias en las normativas sectoriales podría determinarse que no existe posible aplicación del artículo 1205 del CC a los contratos de suministros ya que no parece posible una subrogación tácita en esta relación contractual. Por lo que en el caso de haber saldado la deuda perteneciente al suministro disfrutado por el anterior propietario no tiene como resultado la subrogación tácita en el contrato de suministro y podría repetir contra el titular del contrato de suministro.

\section{b. Segundo supuesto: El nuevo propietario no satisface la deuda anterior a ser usuario efectivo de la energía}

En este caso, el nuevo propietario entiende que no es parte de la relación contractual anterior y por ello no debe satisfacer deuda alguna. Entonces ¿de qué opciones dispone el nuevo propietario para garantizar a su inmueble el suministro de energía? Cuando se adquiere la propiedad de un bien inmueble donde existe un contrato de suministro con el propietario primitivo, el nuevo propietario tiene tres opciones.

La primera opción es subrogarse en el contrato preexistente, esto significa que adquirirá la posición del anterior titular del contrato con las condiciones contractuales que el anterior titular había contratado. La subrogación debe ser aprobada de forma expresa por el acreedor (la empresa suministradora) y está condicionada a que la persona que va a subrogarse no tenga deudas pendientes, en este caso, la empresa no admitirá la subrogación y exigirá el pago previo.

Otra opción de la que dispone el nuevo propietario es el cambio de titularidad, esto implica que el nuevo propietario se convierte ahora en titular del punto de suministro, pero puede contratar otro plan de precios. La ventaja es que no tendrá que incurrir en costes de nuevo alta (enganche, verificación de instalaciones...). También aquí se exige que el anterior titular esté al corriente del pago de deudas. Si hay deudas, se condicionará el cambio al pago.

La tercera opción es dar de alta un nuevo contrato. En este caso, el nuevo propietario celebra una contratación totalmente independiente de la que existía por el anterior propietario del bien inmueble. Esto implica que va a tener que solicitar un nuevo alta en la red de distribución con los correspondientes costes en tiempo y dinero (alta, enganche, verificación de instalaciones...).

\footnotetext{
26 El hecho de cambiar la domiciliación de la cuenta bancaria puede amprarse bajo el patrocinio del
} art.1158 del CC. 
¿Y cómo actuaría la empresa suministradora? La empresa suministradora se encontraría con el siguiente problema: el incumplimiento del contrato del suministro que garantiza el servicio al bien inmueble ${ }^{27}$.

Este incumplimiento contractual debe ser reclamado al deudor que se obligó a cumplir con las prestaciones que derivaron de la relación contractual con la empresa suministradora tal y como se ha observado en los apartados anteriores, aunque caben ciertos matices.

La empresa suministradora como acreedor de esta deuda tiene diversos remedios legales para hacer frente a este incumplimiento: reclamación de pago, resolución del contrato (suspensión del suministro por impago) e indemnización de daños.

El incumplimiento de las obligaciones del contrato de suministro dota a las empresas suministradoras de poder ejecutar cortes de suministro de energía. De forma específica para el suministro de gas, en el artículo 28 del RD 1085/1992 se establecen las causas de resolución del contrato de suministro, entre las que se encuentra "por falta de pago del gas suministrado", esto conllevaría en la práctica la terminación del servicio de suministro por la resolución de la relación contractual. Para el suministro de energía, en el artículo 90.1 del RD 1955/2000 igualmente se establece "La interrupción del suministro por impago o por alguna de las causas establecidas en la presente sección durante más de dos meses desde la fecha de suspensión, determinará la resolución del contrato de suministro o de acceso". Así, el nuevo propietario del bien inmueble vería suprimido su suministro energético, soportando así las consecuencias del incumplimiento de una relación contractual en la cual no formó parte.

Igualmente, la empresa suministradora puede ampararse bajo la exceptio non adimpleti contractus en virtud del artículo 1124 del $\mathrm{CC}^{28}$ para resolver las obligaciones $y$, por ende, provocar el corte del suministro energético del bien inmueble hasta que el nuevo propietario realice un nuevo contrato de suministro. ¿sería esto considerada una práctica abusiva de las empresas comercializadoras?, doctrinalmente se ha entendido la exceptio non adimpleti contractus tanto como una manera de compeler por parte del acreedor al efectivo cumplimiento de la deuda como la consideración de esta excepción una garantía del equilibrio en la relación obligacional.

En todo caso, si se considerara que la empresa suministradora utilizase la excepción de incumplimiento contractual para así impulsar el cumplimiento de la obligación recíproca por el deudor, no constituiría una práctica abusiva, ya que no se obliga al nuevo propietario al pago de la deuda para la celebración de un nuevo contrato de suministro, sino que precisamente debido a la naturaleza del contrato personal del contrato de suministro, el nuevo titular del bien inmueble, que se ve afectado por el

\footnotetext{
27 Relativo al suministro de gas el RD 1434/2002 establece en su art.22.2.d) la obligación de pago de los suministros.

28 "La facultad de resolver las obligaciones se entiende implícita en las recíprocas, para el caso de que uno de los obligados no cumpliere lo que le incumbe".
} 
corte del suministro, solo tendría que realizar un nuevo contrato para que su suministro volviese a ser garantizado.

Estas afirmaciones parecen poner de relieve que las empresas suministradoras pierden fuerza coercitiva para el impulso del cumplimiento de las obligaciones recíprocas, solo manteniendo esta posición de presión sobre el deudor bajo el art.26.b) del RD 1085/1992, pero estas empresas tienen un amplio abanico legal para hacer cumplir con las obligaciones pactadas, como la interposición de una acción de reclamación de cantidad contra el anterior propietario y finalmente podrá embargar los bienes que haya en el patrimonio del deudor sin tener un derecho especialmente privilegiado sobre la casa a la que proporciona suministro (ya que no ostenta naturaleza real).

\section{c. Tercer supuesto: El nuevo propietario disfruta de los suministros sin subrogarse, cambiar la titularidad o dar un nuevo alta y no paga las facturas relativas a su consumo}

En este caso, el nuevo propietario disfruta de los suministros contratados por el anterior propietario y titular del contrato sin formalizar ninguna de las exigencias de la normativa sectorial (subrogación, cambio de titularidad, nuevo alta).

Cabe poner de manifiesto que la CNMC dejó abierta la posibilidad no de subrogación tácita, pero sí de contratación tácita, cuando un nuevo propietario no actuase de forma diligente dando de alta un nuevo contrato y pasando a disfrutar de los suministros contratados por el anterior titular, lo que sin embargo no es causa para solicitarle impagos anteriores a la fecha en la cual se entiende perfeccionada esta contratación tácita ${ }^{29}$.

Esta hipótesis de contratación tácita o subrogación tácita encubierta consistiría en el supuesto de hecho donde el nuevo propietario del bien inmueble disfrutara de los servicios (se convierte en usuario de la energía) cambiando únicamente la domiciliación de la cuenta pudiendo así evitar costes en tiempo y dinero (alta, enganche o verificación de instalaciones ${ }^{30}$ ) que conllevaría un nuevo alta, de igual forma, si este nuevo propietario tuviera deudas con las empresas suministradoras, con esta contratación tácita podría eludir la exigencia de la garantía exigida por las empresas suministradoras. Esto en último término viene a significar que el nuevo propietario con su actuación se beneficia de un enriquecimiento ilícito (disfrutando del suministro con los derechos de alta a pesar de tener deudas pendientes, o no teniendo que soportar los costes relativos a un nuevo alta) mientras que otros usuarios no gozarían de esta ventaja con su actuación legal y diligente.

\footnotetext{
${ }^{29}$ COMISIÓN NACIONAL DE ENERGÍA, "Informe sobre la consulta remitida por una empresa sobre a quien corresponde sufragar las facturas impagadas de suministros de gas pendientes tras la venta de una vivienda particular". Mayo 2012. (8 páginas). Disponible en https://www.cnmc.es/expedientes/cne1812 ${ }^{30}$ Para el suministro de gas arts. 23-30 del RD 1434/2002 y para el suministro energético art.16.8 de la LSE
} 
Además, en este supuesto, el usuario efectivo de la energía no paga las facturas alegando no ser el titular de la relación contractual. ¿Puede dirigirse contra él la empresa suministradora? De acuerdo a la argumentación expuesta a lo largo del artículo donde se consolida la naturaleza personal de las cargas relativas a los contratos de suministro, la empresa suministradora no puede reclamar como deudor directo al nuevo titular ni puede embargar la casa por estas facturas impagadas a pesar de ser el usuario efectivo de la energía. La empresa suministradora debe reclamar estas facturas impagadas al titular del contrato, a pesar de que no haya disfrutado de estos servicios.

¿Y qué ocurre si el anterior propietario y titular del contrato de suministro se encuentra en paradero desconocido o es insolvente? En este caso ¿qué posibilidad tiene la empresa suministradora?

La empresa suministradora tendrá la posibilidad de interponer una acción directa contra el nuevo propietario por los nuevos consumos mediante una acción de enriquecimiento sin causa de forma subsidiaria al no poder satisfacer la deuda por el titular del contrato ${ }^{31}$.

Esta acción se fundamenta según la jurisprudencia en la adquisición de una ventaja patrimonial y correlativamente un empobrecimiento de otra parte, con relación de causalidad entre la ventaja patrimonial (enriquecimiento) y el empobrecimiento y con ausencia de razón jurídica o justificación que lo legitime ${ }^{32}$. Tal y como determina numerosa jurisprudencia del TS «nadie debe enriquecerse injustamente o sin causa a costa de otro, se aplica de forma subsidiaria, en defecto de ley y de costumbre, y también informa el Derecho patrimonial, para evitar que puedan producirse enriquecimientos injustos, y contribuye a su interpretación en tal sentido. Como institución jurídica autónoma (enriquecimiento sin causa), y sin perjuicio de las eventuales previsiones legales, su aplicación descansa sobre la concurrencia de un elemento económico (la ganancia de uno, correlativa al empobrecimiento de otro,

\footnotetext{
${ }^{31}$ La acción de enriquecimiento sin causa ha sido considerada como subsidiaria a través de la construcción jurisprudencial, así «la concreción de la aplicación subsidiaria de la acción comporta, entre otros extremos, las siguientes consideraciones:

- Si con la pretensión del enriquecimiento injustificado se pide lo mismo o no que otra acción al servicio del actor.

- Si la pretensión de fondo del enriquecimiento injustificado viene ya regulada por normas concretas o por la previsión normativa.

- Si la norma preferente de aplicación elimina, expresa o indirectamente, cualquier otra vía que teniendo idéntico o distinto fundamento persiga un mismo resultado u otro parecido.

- Si el ordenamiento jurídico al señalar una acción específica y preferente otorga un plazo de prescripción con el que ha pretendido cerrar la cuestión ante cualquier otra posibilidad de reclamación referida al mismo objeto, a sus subrogados o parte de él.

- Si la acción específica y preferente ha perdido la viabilidad del éxito por defecto de prueba o interacción de alguna causa imputable al actor»

32 Así se pronuncia el TS en sentencia no 467/2012 de 19 de julio de 2012 «Ha de recordarse que para que exista un enriquecimiento realmente injusto $y$, por tanto, antijurídico, es preciso que se demuestre que alguien ha adquirido una utilidad que no provenga del ejercicio sin abuso de un derecho legítimo atribuido por un contrato, por una sentencia judicial o por un precepto legal»
} 
mediando un nexo de causalidad entre ambas), y una condición jurídica (la ausencia de causa justificativa) $)^{33} \gg$

En este caso, la empresa suministradora podrá satisfacer a través de esta acción de enriquecimiento sin causa el montante impagado relativo a los nuevos consumos disfrutados por el nuevo propietario del bien inmueble, quedando aun así sin satisfacer las deudas anteriores ${ }^{34}$.

\section{Conclusiones}

Una vez analizado todas las vicisitudes de este tipo de contratos y su relación con el bien inmueble, se ha determinado tanto por la normativa como por la doctrina y la jurisprudencia que no existe afección al bien inmueble. Son considerados como cargas puramente personales que solamente obligan a las partes que bajo su manifestación de la voluntad decidieron perfeccionar este tipo de contrato.

Por todo ello, el nuevo propietario no deberá hacer frente a las deudas impagadas relativas al periodo anterior a ser el propietario del bien inmueble. Las compañías suministradoras deberán dirigirse contra el anterior propietario y no podrán condicionar al nuevo propietario al pago de dichas deudas para poder contratar con ellas un nuevo régimen contractual, ya que, en ese caso, será calificada de práctica comercial abusiva.

Para el caso de las facturas impagadas por el nuevo propietario relativas al periodo de tiempo en el cual ya era propietario del bien inmueble y había disfrutado de estos servicios, las compañías suministradoras deberán reclamar estas facturas impagadas al anterior propietario ya que el contrato no había finalizado ni tampoco se había producido subrogación del deudor.

Esto no lleva a concluir de manera automática que el nuevo propietario podría disfrutar de los suministros sin tener que hacer frente a sus facturas, aprovechando la deficiente diligencia del anterior propietario. El anterior propietario será procesalmente el legitimado pasivo de esta reclamación de cantidad, pero posteriormente podrá ejercer una acción de repetición contra el nuevo propietario.

Y no solo se vería afectado el nuevo propietario por esta posible acción de repetición del titular primitivo del bien inmueble, sino que las empresas suministradoras de energía disponen de un abanico de remedios legales que implicarían principalmente el corte del suministro al nuevo bien inmueble y la interposición frente a él de una acción de enriquecimiento sin causa.

\section{8. ¿Qué ocurriría con la Tasa de Residuos Urbanos?}

En el caso de que existiesen deudas relativas a impagos de la Tasa de Residuos Urbanos cuando se adquiere la propiedad de un bien inmueble, responderá de la deuda tributaria por esta tasa, el titular del bien inmueble en el momento del

\footnotetext{
${ }^{33}$ Sentencia del TS (Sala de lo Civil, Sección1a) núm. 82/2016 de 19 febrero (RJ 2016\710)

${ }^{34}$ Así ocurre en el supuesto de la sentencia de la AP de Madrid (Sección 25a) núm. 560/2009 de 4 diciembre. (JUR 2010\69702)
} 
nacimiento del hecho imponible, lo que en último término viene a manifestar que no se puede calificar esta obligación como una carga propter rem. La deuda personal no se transmite con la propiedad convirtiendo en deudor al adquirente y nuevo propietario. Por lo que en esta tasa municipal si el comprador no ha sido partícipe de inicio en la relación jurídico-tributaria no se convertirá posteriormente en obligado al pago de esa tasa impagada por el anterior titular.

Tampoco cabe calificar esta tasa como una carga real, el incumplimiento de este deber tributario no goza de afección al bien inmueble y el nuevo propietario no tendrá que soportar la posibilidad de embargo por la Administración Tributaria en caso de impago con la finalidad de la satisfacción de su deuda. Esta tasa ostenta naturaleza personal derivado de su ligamiento a la persona que se constituye como sujeto pasivo de esta obligación tributaria ${ }^{35}$.

Esta interpretación se ve apoyada por dos motivos: La imposibilidad de conocer en registro público el impago de esta Tasa lo que implica en último término la inoponibilidad a terceros y como segundo motivo se esgrime la falta expresa en la ley sobre la afección real de esta tasa al inmueble ${ }^{36}$.

\section{Bibliografía}

BUERES, A. J. (2012). Obligaciones "propter rem" y sus relaciones con otras figuras. Lecciones y ensayos(90).

CAÑIZARES LASO, A., DE PABLO CONTRERAS, P., ORDUÑA MORENO, J., \& VALPUESTA FERNÁNDEZ, R. (2011). Código Civil Comentado. Libro IV-Obligaciones y contratos. Teoría general de la obligación y el contrato. (Arts.1088 a 1444) (Primera ed., Vol. III). Madrid: Civitas.

CARRASCO PERERA, A. (2021). Derecho de Contratos (Tercera ed.), ISBN: 978-841345-737-6, Aranzadi.

CERDEIRA BRAVO DE MANSILLA, G. (2008). Derecho o carga real: naturaleza jurídica de la hipoteca. Revista de Derecho Patrimonial, 47-163.

DÍEZ-PICAZO, L. (1995). Fundamentos del derecho civil patrimonial. Las relaciones jurídico-reales. El registro de la propiedad. La posesión (Cuarta ed., Vol. III). Madrid: Civitas.

FERNÁNDEZ BENAVIDES, M. (Junio de 2012). ¿Quién debe sufragar las facturas impagadas de suministros de gas pendientes tras la venta de la vivienda? Obtenido

\footnotetext{
35 TENREIRO BORREGÓN-GARCÍA, R., "Responsabilidad tributaria en la adquisición de inmuebles". Periódico Expansión. (https://www.expansion.com/juridico/opinion/2018/06/16/5b239d61ca4741711e8b4621.html). Junio 2018.

${ }^{36}$ Así, se pronuncia la sentencia del Tribunal Superior de Justicia de País Vasco, (Sala de lo ContenciosoAdministrativo) núm. 869/1996 de 29 noviembre. (JT 1996\1613).
} 
de Centro de Estudios de Consumo de la Universidad de Castilla-La Mancha: http://www.uclm/cesco.es/

(CNMC). Informe sobre la consulta remitida por una empresa sobre a quién corresponde sufragar las facturas impagadas de suministros de gas pendientes tras la venta de una vivienda particular. (2012) Comisión Nacional de Energía, Madrid. Obtenido de https://www.cnmc.es/expedientes/cne1812

MARIÑO PARDO, F. M. (Julio de 2020). Las cargas en la compraventa 1. El artículo 1483 del Código Civil. EL delito de estafa inmobiliaria: sus posibles consecuencias civiles. La libertad de cargas en la legislación de protección de los consumidores. El pacto de transmisión libre de cargas. Obtenido de Iuris Prudente: Blog de derecho privado, desde la óptica notarial y registral.: http://www.iurisprudente.com/2020/07/las-cargas-en-la-compraventa-1-el.html

MENDOZA LOSANA, A. I. (2012). ¿Pueden los usuarios de suministros no titulares del contrato reclamar contra el suministrador? Centro de Estudios de Consumo, 9. Obtenido de www.centrodeestudiosdeconsumo.com

MENDOZA LOSANA, A. I. (2018). Medidas contra la pobreza energética y de protección de los consumidores en el Real Decreto Ley 15/2018, de 5 octubre. Centro de Estudios de Consumo. Obtenido de www.centrodeestudiosdeconsumo.com

MORETON SÁNCHEZ, M. F. (2006). UNED. Universidad Nacional de Educación a Distancia (España). La expromisión: el artículo 1205 del Código Civil Español. Obtenido de UNED. Universidad Nacional de Educación a Distancia (España)

PARRA LUCÁN, M. Á., \& LALANA DEL CASTILLO, C. (2011). La protección de los consumidores ante las empresas de telefonía, gas y electricidad. Estudio de cuestiones jurídicas. Oficina Municipal de Información al Consumidor (OMIC).

PICAZO-DIEZ, L. (2008). Fundamentos del derecho civil patrimonial II. Las relaciones obligatorias (Sexta ed., Vol. II). Madrid: Civitas.

RODRIGUEZ MÁRQUEZ, J., \& TERESA CARRASCAL, M. (2006). El impuesto sobre Bienes Inmuebles. Tributos locales y autonómicos, 151-202.

TENREIRO BORREGÓN-GARCÍA, R. (16 de Junio de 2018). Responsabilidad tributaria en la adquisición de inmuebles. Obtenido de Expansión: https://www.expansion.com/juridico/opinion/2018/06/16/5b239d61ca4741711e8b 4621.html 